\title{
Lyophilisate for Solution for Injection Dosage Form
}

National Cancer Institute

\section{Source}

National Cancer Institute. Lyophilisate for Solution for Injection Dosage Form. NCI

Thesaurus. Code C149642.

Solid sterile preparation for veterinary use consisting of a freeze-dried powder intended to be dissolved in the specified liquid to obtain a solution for injection. 